\title{
Turizm Fakültesi Öğrencilerinin Seçmeli Yabancı Dil Derslerine (Almanca, Fransızca ve İtalyanca) Yönelik Kaygı Düzeylerinin İncelenmesi
}

\author{
Bilal Üstün (iD), Nevşehir \\ do) https://dx.doi.org/10.37583/diyalog.958495
}

$\ddot{O} z$

Bu çalışmada Turizm Fakültesi öğrencilerinin seçmeli yabancı dil derslerine (Almanca, Fransızca ve İtalyanca) yönelik kaygı düzeylerinin çeşitli değişkenlere göre incelenmesi amaçlanmaktadır. Araşıırmada nicel araştırma yöntemlerinden tarama modeli kullanılmıştır. Araştırmanın evrenini Türkiye'de Turizm Fakültelerinde eğitim alan öğrenciler oluşturmaktadır. Araştırmanın örneklemini ise bir devlet üniversitesinin Turizm Fakültesinde eğitim alan ikinci, üçüncü ve dördüncü sinıf öğrencileri oluşturmaktadır. Araştırmaya toplam 141 öğrenci katılmıştır. Katılımcıların \%46,1'i kadın, \%53,9’u ise erkektir. Çalışmada veri toplama araçları olarak araştırmacı tarafından oluşturulan kişisel bilgi formu ile Horwitz, Horwitz ve Cope (1986) tarafından geliştirilmiş "yabancı dil dersi kaygı ölçeği” kullanılmıştır. Ölçek 33 madde ve 3 alt boyuttan oluşmaktadır. Araştırmada yer alan verilerin analizinde SPSS 22 paket programı kullanılmıştır. Örnekleme ait istatistikler frekans analiz ile hesaplanmıştır. Bağımsız değişkenlerin hesaplanmasında t-testi ve tek yönlü varyans analizi (ANOVA) testleri kullanılmıştır. Tüm hesaplamalarda anlamlılık düzeyi $\mathrm{p}<, 05$ olarak kabul edilmiştir. Araştırmanın sonucunda, "dil dersinde konuşma kaygısı" boyutunda erkek öğrencilerin kadın öğrencilere göre daha kaygılı oldukları; eğitim alınan bölüm değişkenine bağlı olarak "dil dersine yönelik ilgi" ve "yabancılarla konuşma kaygısı" boyutlarında anlamlı bir şekilde farklılaştı̆̆ı eğitim alınan sınıf düzeyi değişkenine göre herhangi bir farka rastlanmadığı; seçilen yabancı dil değişkenine bağlı olarak yalnızca "yabancılarla konuşma kaygısı" boyutunda anlamlı şekilde farklılaştı̆̆ mezuniyet sonrası plan değişkenine bağlı olarak ise yalnızca "dil dersinde konuşma kaygısı" boyutunda anlamlı farklılık gösterdiği ortaya konmuştur.

Anahtar Sözcükler: Seçmeli yabancı dil, kaygl, Almanca, Fransızca, İtalyanca.

\section{Abstract \\ A Study About the Anxiety Level of The Students of The Faculty of Tourism in Relation to the Elective Foreign Language (German, French and Italian)}

The aim of this study is to examine the anxiety level among students in the Faculty of Tourism regarding the elective foreign language classes (German, French and Italian) using various variables. In the study, survey research model, one of the quantitative research methods, was employed. The population of the study consisted of the students who study at the Faculties of Tourism in Turkey. The sample of the study consists of the Students of a Faculty of Tourism who are in their first, second and third year of study at a state university. 141 students participated in the research. $46.1 \%$ of the participants are female and $53.9 \%$ 
male. The study used a personal information form developed by the researcher and the "The Foreign Language Classroom Anxiety Scale" developed by Horwitz, Horwitz and Cope (1986) as data collection tools. The scale consists of 33 items and 3 sub-dimensions. SPSS 22 package program was used to analyse the data in the research. The statistics of the sample were calculated by frequency analysis. T-test and one-way analysis of variance (ANOVA) tests were used to calculate independent variables. In all calculations, the level of significance was accepted as $p<.05$. As results of the study, it has been revealed that male students are more anxious than female students in the dimension of "speaking anxiety in language classes"; depending on the variable of the subject, the dimensions of "interest in language classes" and "anxiety about speaking with foreigners" differ significantly; there was no difference according to the variable of grade level; depending on the selected foreign language variable, it differs significantly only in the dimension of "speaking anxiety with foreigners"; there was no difference according to the success variable and that there is a significant difference only in the dimension of "speaking anxiety in language classes" depending on the postgraduate plan variable.

Keywords: Elective foreign language, anxiety, German, French, Italian. 


\section{EXTENDED ABSTRACT}

When examining the literature, many studies on foreign language teaching in the faculties of tourism were found (Akgöz/ Gürsoy 2014; Altürk et al. (2016); Büyükkalay 2016; Davras/ Bulgan 2012; İşigüzel 2013; Uysal, 2019; Üstün 2015)). The common point in these studies is that they emphasise the importance of foreign language lessons given in the faculties of tourism. When analysing the websites of universities in Turkey with a faculty for tourism, it is found that, besides English, mostly Western languages such as German, French and Italian are offered. Considering that the family of languages these languages belong to is different from Turkish, it can be said that learning these languages has its own difficulties. This, in turn, may cause anxiety in students regarding the foreign language. "Anxiety, in its broad sense, is defined as an emotional state in which a feeling of powerlessness is experienced while preparing for a perceived danger" (Aydın/ Zengin 2008: 84). It is known that high levels of anxiety have negative results, while medium levels of anxiety have positive results. Akgun et al. (2007; cited from Doğan/ Çoban 2009: 160) argues that "a high level of anxiety leads to the individual returning to simpler behaviors, being anxious and overly focused on satisfying".

The aim of this study is to examine the anxiety level among students in the Faculty of Tourism regarding the elective foreign language classes (German, French and Italian) using various variables. For this purpose, answers to the research questions below were sought.

a. Do faculty of tourism students' anxiety about elective foreign language classes differ according to their sex?

b. Do faculty of tourism students' concerns about elective foreign language classes differ according to their departments?

c. Do faculty of tourism students' anxiety about elective foreign language classes differ according to their academic year?

d. Do faculty of tourism students' anxiety about elective foreign language classes differ according to the foreign languages they choose?

e. Do faculty of tourism students' anxiety about elective foreign language classes differ according to their success?

f. Do faculty of tourism students' anxiety about elective foreign language classes differ depending on whether they want to work in the field of tourism or not?

In the study, survey research model, one of the quantitative research methods, was employed. The survey research model is a research model that aims to describe a situation that existed in the past or continues to exist as it is. In the survey research model, the object, event or individual subject to research is tried to be defined in its own conditions and as it is" (Karasar 2009; cited in Yavuz/ Akdeniz 2019: 216). 
The population of the study consisted of the students who study at the Faculties of Tourism in Turkey. Since it was not possible to collect data from all students in the population, sampling was preferred (Şen 2011). The sample of the study consists of the students of a Faculty of Tourism who are in their first, second and third year of study at a state university. 141 students participated in the research. $46.1 \%$ of the participants are female and $53.9 \%$ male.

The study used a personal information form developed by the researcher and the "Foreign Language Classroom Anxiety Scale" developed by Horwitz, Horwitz and Cope (1986) as data collection tools. The scale consists of 33 items and 3 subdimensions. The sub dimensions of the scale were revealed as; (1) (DDKK) speaking anxiety in language classes $(1,2,3,4,7,8,9,15,16,18,22,23,24,26,27,28,29,31$, $33)$, (2) (DDYI) interest in language classes $(6,11,17)$ and (3) (YKK) anxiety about speaking with foreigners $(14,19,32)$. In order to increase the reliability of the scale, negative expressions were included in the questions $(2,5,14,22)$. The validity and reliability study of the scale was conducted by Gürsu (2011) and in the exploratory factor analysis, the Kaiser-Meyer-Olkin value was calculated as ,812.). The scale is prepared in 5-point Likert type and the options in the scale are; (1) Strongly agree, (2) Agree, (3) No idea, (4) Disagree, and (5) Strongly Disagree. In this study, the Cronbach's Alpha $(\alpha)$ value of the scale was calculated as ,866. In the personal information form used in the research, the participants were asked about (1) their sex, (2) their subject, (3) their academic year, (4) their chosen foreign language, (5) their success status, and (6) whether they would like to work in tourism after graduation or not.

SPSS 22 package program was used to analyse the data in the research. The statistics of the sample were calculated by frequency analysis. T-test and one-way analysis of variance (ANOVA) tests were used to calculate independent variables. In all calculations, the level of significance was accepted as $p<.05$.

As results of the study, it has been revealed that male students are more anxious than female students in the dimension of "speaking anxiety in language classes"; depending on the variable of the subject, the dimensions of "interest in language classes" and "anxiety about speaking with foreigners" differ significantly; there was no difference according to the variable of grade level; depending on the selected foreign language variable, it differs significantly only in the dimension of "speaking anxiety with foreigners"; there was no difference according to the success variable and that there is a significant difference only in the dimension of "speaking anxiety in language classes" depending on the postgraduate plan variable.

In order to reduce the anxiety of students of the faculties of tourism towards foreign language classes, it is believed that it would be appropriate, to give information seminars about the importance of foreign language and that it is not as difficult as it is thought; to increase the foreign language course hours, to expose students to foreign languages more and to conduct this study with a higher number of participants and a larger sample in the future. 


\section{Giriş}

Yabancı dil ve yabancı dil eğitimi tüm dünyada olduğu gibi Türkiye'de de önemli bir konuma sahiptir. "Artık yabancı bir dilin yeterli olmadığı günümüzde, entelektüel bir meslekleşmeye doğru gidildiği görülmekte olup, bilgisayar ve yabancı dil bilmek çağa yetişmek, onu yakalayabilmek için olmazsa olmaz koşuttur" (Çelebi 2006: 286). Işık (2008: 15) “Türkiye'de yabancı dil öğretimi konusunda batılılaşma çalışmaları ile birlikte büyük uğraş verildiğini, bu konuda hem kamusal hem de bireysel boyutta ciddi zaman ve kaynak harcandığını" ifade etmektedir. Yabancı dilin ve yabancı dil eğitiminin her alan da olduğu gibi turizm alanında da büyük bir öneme sahip olduğu söylenebilir. "Turizm sektöründe istihdam edilecek personelde ön plana çıkan özellik yabanc1 dil bilgisidir" (Davras/ Bulgan 2012: 228). Yabanc1 dil bilgisine sahip olmayan personelin gelen yabancı misafirleri memnun etmesi olanaksızdır. Akgöz ve Gürsoy (2014: 22) "misafirlere iyi hizmet edebilmenin, yeterli kalifiye personel varlığına ve personelin yabancı dil bilgisine bağlı olduğunu" ifade etmektedir. "Turizm sektöründe başlangıç yıllarında, kısa süreli hizmet içi eğitimlerle ve kurslarla sürdürülen mesleki eğitimi ilerleyen yıllarda, en az ortaöğretim düzeyinde, sonraki dönemlerde ise yükseköğretim düzeyinde eğitime gereksinim göstermeye başlamıştır" (Akoğlan Kozak 2009: 2). Bugün Türkiye'de turizm alanına nitelikli elemanların yetiştirildiği Turizm Fakültelerinde de buna bağlı olarak öğrencilere yabancı dil eğitimi verilmektedir. "Lisans düzeyinde turizm eğitiminde temel amaç, turizm sektörüne bilgili, yabancı dil bilen yetkin bireyler yetiştirmektir" (Akdoğan Kozak 2009: 2). Türkiye'deki Turizm Fakültelerinde birinci yabancı dil İngilizceye ek olarak ikinci bir seçmeli yabancı dil dersi sunulmaktadır. Bu eğitimin öğrenciler kadar toplumsal açıdan da gerekli olduğu söylenebilir. "İkinci yabancı dilin okullarda öğretilmesi, sadece iş hayatında ve iletişim alanlarında sağlayacağı avantajlardan ötürü değil, Avrupa Birliği'ne dahil olma hedefi olan Türkiye'nin Avrupa Birliği ile uyum içerisinde olabilmesi için de gereklidir" (Koçak/ Çobanoğulları 2017: 2). Literatür incelendiğinde Turizm Fakültelerinde verilen yabancı dil dersleri ile ilgili yapılmış birçok çalışmaya rastlanmıştır (Akgöz/ Gürsoy 2014; Altürk vd. (2016); Büyükkalay 2016; Davras/ Bulgan 2012; İşigüzel 2013; Uysal 2019; Üstün 2015). Bu çalışmalardaki ortak nokta, Turizm Fakültelerinde verilen yabancı dil derslerine yönelik önemi vurguluyor olmalarıdır. Türkiye' de turizm eğitimi veren üniversitelerin internet sayfaları incelendiğinde, İngilizce dışında verilen yabancı dillerin genellikle Almanca, Fransızca ve İtalyanca gibi batı dilleri olduğu tespit edilmiştir. $\mathrm{Bu}$ dillerin bağlı olduğu dil ailesinin Türkçeden farklı olduğu düşünüldüğünde bu dilleri öğrenmenin de kendine göre zorlular taşıdığı söylenebilir. Bu da öğrencilerde yabancı dile yönelik kaygı oluşturabilir. "Kaygı, geniş anlamı ile sezilen bir tehlikeye hazırlanma sırasında algılanan güçsüzlük duygusunun yaşandığı duygusal bir durum olarak tanımlanmaktadı" (Aydın/ Zengin 2008: 84). Duyulan kayg1 düzeyinin yüksek olmasının olumsuz, orta düzeyde olmasının ise olumlu sonuçlar doğurduğu bilinmektedir. Akgün vd., "kaygı düzeyinin yüksek olmasının, bireyin daha basit davranışlara gerilemesine, endişeli olmasına ve memnun etmeye aşırı odaklanmasına neden olduğunu savunmaktadır. Bununla birlikte "orta düzeydeki kaygının organizmayı uyarıcı, koruyucu ve motive edici özelliği olduğuna vurgu 
yapmaktadır. Kaygı iyi yönetildiğinde bireyin başarılı olmak için daha fazla çalışmasına, yaşanacak olumsuzluklara karşı önlem almasına yardımcı olduğunu" belirtmektedir (2007; akt. Doğan/ Çoban 2009: 160). Literatür incelendiğinde yabancı dil öğretiminde kaygı ile ilgili birçok çalışmanın yapıldığı görülmektedir. Ergür (2004) çalışmalarında, yabancı dil öğreniminde öğrencinin hem sürece etkin katılımını hem de sürecin sonundaki başarısını olumsuz yönde etkileyebilen kaygı konusunu tartışmaktadır. Tuncer ve Temur (2017) da çalışmasında yabancı dil hazırlık eğitimi alan öğrencilerin yabancı dile yönelik kaygı ve başarıları arasındaki ilişkileri ele almışlardır. Genç (2009) de çalışmasında benzer bir konuyu ele alarak Yabancı Diller Yüksekokulu öğrencilerinin yabancı dil kaygılarını araştırmıştır. Alanyazında birçok benzer çalışmaya rastlamak mümkündür (Baş 2014; Duman vd. 2017; Tuncer/ Akmençe 2019; Yılmaz/ Sakarya Maden 2016; Yılmaz Güngör 2016). Literatür incelemesine göre yabancı dilde kaygı konusunun oldukça popüler bir konu olduğu söylenebilir.

$\mathrm{Bu}$ çalışmada Turizm Fakültesi öğrencilerinin seçmeli yabancı dil derslerine (Almanca, Fransızca ve İtalyanca) yönelik kaygı düzeylerinin çeşitli değişkenlere göre incelenmesi amaçlanmaktadır. $\mathrm{Bu}$ amaç doğrultusunda aşağıda yer alan araştırma sorularına cevap aranmıştır.

a. Turizm Fakültesi öğrencilerinin seçmeli yabancı dil derslerine yönelik kaygıları cinsiyetlerine göre farklılaşmakta mıdır?

b. Turizm Fakültesi öğrencilerinin seçmeli yabancı dil derslerine yönelik kaygıları bölümlerine göre farklılaşmakta mıdır?

c. Turizm Fakültesi öğrencilerinin seçmeli yabancı dil derslerine yönelik kaygıları sınıf düzeylerine göre farklılaşmakta mıdır?

d. Turizm Fakültesi öğrencilerinin seçmeli yabancı dil derslerine yönelik kaygıları seçtikleri yabancı dillere göre farklılaşmakta mıdır?

e. Turizm Fakültesi öğrencilerinin seçmeli yabancı dil derslerine yönelik kaygıları başarı durumlarına göre farklılaşmakta mıdır?

f. Turizm Fakültesi öğrencilerinin seçmeli yabancı dil derslerine yönelik kaygıları Turizm alanında çalışmak isteyip istememelerine göre farklılaşmakta mıdır?

\section{Araştırmanın Modeli}

Araştırmada nicel araştırma yöntemlerinden tarama modeli kullanılmıştır. "Felsefi dayanakları incelendiğinde, pozitivist ve realist paradigmalara dayanan nicel araştırma, elde edilen bulguların, bir şekilde sayısal değerlerle ifade edilmesi ve ölçülebilmesi sürecidir" (Oral/ Çoban 2020: 13). "Tarama modeli ise, geçmişte var olan ya da var olmaya devam eden bir durumu var olduğu haliyle betimlemeyi amaçlayan araştırma modelidir. Tarama modelinde araştırma konusu olan nesne, olay ya da birey, kendi şartları içinde ve olduğu haliyle tanımlanmaya çalışılır” (Karasar 2009; akt. Yavuz/ 
Akdeniz 2019: 216). Bu çalışmada da araştırma konusu kendi şartları içinde ve olduğu haliyle ortaya konmak istendiği için tarama modeli seçilmiştir.

\section{Evren ve Örneklem}

Araştırmanın evrenini Türkiye'de Turizm Fakültelerinde eğitim alan öğrenciler oluşturmaktadır. Evrene giren tüm öğrencilerden veri toplamak mümkün olmadığı için örneklem alma yoluna gidilmiştir (Şen 2011). Araştırmanın örneklemini ise bir devlet üniversitesinin Turizm Fakültesinde eğitim alan ikinci, üçüncü ve dördüncü sınıf öğrencileri oluşturmaktadır. Araştırmaya 141 öğrenci katılmıştır. Örnekleme ait frekans dağılımları Tablo 1'de verilmiştir.

\begin{tabular}{|c|c|c|}
\hline Cinsiyet & $\mathbf{N}$ & $\mathbf{P}(\%)$ \\
\hline Kadın & 65 & 46,1 \\
\hline Erkek & 76 & 53,9 \\
\hline \multicolumn{3}{|l|}{ Bölüm } \\
\hline Turizm İşletmeciliği & 50 & 35,5 \\
\hline Turizm Rehberliği & 45 & 31,9 \\
\hline Gastronomi & 46 & 32,6 \\
\hline \multicolumn{3}{|l|}{ Sinıf } \\
\hline 2. Sinif & 44 & 31,2 \\
\hline 3. Sinıf & 42 & 29,8 \\
\hline 4. Sinif & 55 & 39,0 \\
\hline \multicolumn{3}{|l|}{ Seçmeli Yabancı Dil } \\
\hline Almanca & 45 & 31,9 \\
\hline Fransızca & 58 & 41,1 \\
\hline İtalyanca & 38 & 27,0 \\
\hline \multicolumn{3}{|l|}{ Başarı Durumu } \\
\hline $1,00-2,00$ & 3 & 2,1 \\
\hline $2,01-2,50$ & 21 & 14,9 \\
\hline $2,51-3,00$ & 51 & 36,2 \\
\hline $3,01-4,00$ & 66 & 46,8 \\
\hline \multicolumn{3}{|l|}{ Turizm Alanında İş } \\
\hline Evet & 59 & 41,8 \\
\hline Hayır & 26 & 18,4 \\
\hline Kararsızım & 56 & 39,7 \\
\hline Toplam & 141 & 100 \\
\hline
\end{tabular}

Tablo 1: Örnekleme ait frekans tablosu 
Tablo 1'e göre araştırmaya katılan öğrencilerin \%46,1'i kadın, \%53,9'u ise erkektir. Katılımcıların \%35,5'i Turizm İşletmeciliği/ Turizm İşletmeciliği ve Otelcilik; \%31,9'u Turizm Rehberliği ve \%32,6's1 da Gastronomi bölümünde eğitim almaktadır. Araştırmada yer alan katılımcıların \%31,2'sinin 2.sınıfta; \%29,8'inin 3.sınıfta ve \%39'unun ise 4.sınıfta eğitim aldıkları görülmektedir. Katılımcıların \%31,9'u ikinci yabancı dil olarak Almancayı; \%41,1'i Fransızcayı ve \%27'si de İtalyancayı seçtiklerini belirtmişlerdir. Öğrencilerin başarı durumları incelendiğinde ise \%2,1'inin genel not ortalamasinin 1,00-2,00 arasi; \%14,9'unun 2,01-2,50 aras1; \%36,2'sinin 2,51-3,00 aras1 ve \%46,8'inin de 3,01-4,00 arası olduğu görülmektedir. Katılımcıların \%41,8'i mezun olduklarında mutlaka turizm alanında çalışmak istediklerini; \%18,4'ü turizm alanında çalışmak istemediklerini ve \%39,7'si ise kararsız olduklarını belirtmişlerdir.

\section{Veri Toplama Aracı}

Çalışmada veri toplama araçları olarak araştırmacı tarafindan oluşturulan kişisel bilgi formu ile Horwitz, Horwitz ve Cope (1986) tarafından geliştirilmiş "yabancı dil dersi kaygı ölçeği”" kullanılmıştır. Ölçek 33 madde ve 3 alt boyuttan oluşmaktadır. Ölçeğin alt boyutları; (1) (DDKK) dil dersinde konuşma kaygısı (1, 2, 3, 4, 7, 8, 9, 15, 16, 18, 22, 23, 24, 26, 27, 28, 29, 31, 33), (2) (DDYİ) dil dersine yönelik ilgi $(6,11,17)$ ve (3) (YKK) yabancılarla konuşma kaygısı $(14,19,32)$ olarak ortaya çıkarılmıştır. Ölçeğin güvenirliğinin artırılması amacıyla sorularda olumsuz ifadelere yer verilmiştir $(2,5,14$, 22). Ölçeğin geçerlik güvenirlik çalışması Gürsu (2011) tarafından yapılmış ve açımlayıcı faktör analizinde Kaiser-Meyer-Olkin ölçüm değeri ,812 olarak hesaplanmıştır. Ölçek 5'li Likert tipinde hazırlanmış ve ölçekte yer alan seçenekler; (1) Büyük ölçüde katılıyorum, (2) Katılıyorum, (3) Fikrim yok, (4) Katılmıyorum ve (5) Kesinlikle Katılmıyorum şeklinde belirlenmiştir. Bu çalışmada ölçeğin Cronbach Alpha $(\alpha)$ değeri ,866 olarak hesap edilmiştir. Araştırmada kullanılan kişisel bilgi formunda ise katılımcılara; (1) cinsiyetleri, (2) bölümleri, (3) sınıf düzeyleri, (4) seçtikleri yabancı dilleri, (5) başarı durumları ve (6) mezun olduktan sonra turizm alanında çalışmak isteyip istemedikleri sorulmuştur. Katılımcılara, araştırmaya katılımlarının tamamen gönüllülük esasına bağlı olduğu iletilmiş ve katılımcılar araştırmacı tarafindan çalışma ile ilgili detaylı bir şekilde bilgilendirilmiştir.

\section{Verilerin Analizi}

Araştırmada yer alan verilerin analizinde SPSS 22 paket programı kullanılmıştır. Örnekleme ait istatistikler frekans analiz ile hesaplanmıştır. Bağımsız değişkenlerin hesaplanmasında t-testi ve tek yönlü varyans analizi (ANOVA) testleri kullanılmıştır. Tüm hesaplamalarda anlamlılık düzeyi $\mathrm{p}<, 05$ olarak kabul edilmiştir. 


\section{Bulgular}

$\mathrm{Bu}$ bölümde katılımcıların seçmeli yabancı dil derslerine yönelik kaygılarının belirlenmiş değişkenlere göre anlamlı bir şekilde farklılık gösterip göstermediği incelenerek tablolar halinde sunulmuştur. İncelemelerde t-testi ve tek yönlü varyans analizi (ANOVA) testlerinde Post-Hoc Tukey testi kullanılmıştır. İncelemelerde anlamlılık düzeyi $\mathrm{p}<, 05$ olarak kabul edilmiştir.

Katılımcıların yabancı dil dersi kaygılarının cinsiyetlerine göre anlamlı farklılıklar gösterip göstermediği t-testi kullanılarak analiz edilmiştir. Analize ilişkin sonuçlar Tablo 2'de gösterilmiştir.

\begin{tabular}{lcccccc}
\hline Boyut & Cinsiyet & $\mathbf{N}$ & $\mathbf{X}$ & $\mathbf{S D}$ & $\mathbf{t}$ & $\mathbf{p}$ \\
\hline DDKK & Kadın & 65 & 2,68 &, 699 & $-4,62$ &, 000 \\
& Erkek & 76 & 3,18 &, 582 & & \\
\hline DDYİ & Kadın & 65 & 2,63 &, 556 &, 215 &, 830 \\
& Erkek & 76 & 2,60 &, 609 & &, 281 \\
\hline YKK & Kadın & 65 & 3,19 &, 723 & 1,08 & \\
& Erkek & 76 & 3,06 &, 737 & &
\end{tabular}

Tablo 2: Cinsiyet değişkenine bağlı istatistikler

Tablo 2 incelendiğinde cinsiyet değişkeninin yalnızca "dil dersinde konuşma kaygısı" boyutunda anlamlı bir farklılık $(p=, 000<, 05)$ gösterdiği görülmektedir. "Dil dersinde konuşma kaygısı" boyunda erkek öğrencilerin kaygı düzeylerinin $(X=3,18)$ kadın öğrencilerin kaygı düzeylerinden $(X=2,68)$ daha yüksek olduğu söylenebilir. Diğer boyutlar incelendiğinde anlamlı farklılıklarla karşılaşılmadı̆̆ $(\mathrm{p}=, 830>, 05 / \mathrm{p}=, 281>, 05)$.

Katılımcıların yabancı dil dersi kaygılarının bölümlerine göre anlamlı bir şekilde farklılaşıp farklılaşmadığı tek yönlü varyans analizi (AVONA) testlerinden Post-Hoc Tukey testi kullanılarak hesaplanmıştır. Post-Hoc Tukey testlerine ilişkin istatistiki sonuçlar Tablo 3 'te verilmiştir. 


\begin{tabular}{llllllll}
\hline Boyut & Bölüm & N & X & SD & Min. & Max. & p \\
\hline DDKK & & & & & & & \\
& Tí/ Tío & 50 & 2,87 &, 769 & 1,63 & 4,05 & \\
& Tur. Reh. & 45 & 3,07 &, 582 & 1,63 & 4,11 & \\
& Gastronomi & 46 & 2,91 &, 679 & 1,63 & 4,26 &, 345 \\
\hline DDYİ & & & & & & & \\
& Tí/ Tío & 50 & 2,52 &, 579 & 1,33 & 3,67 & \\
& Tur. Reh. & 45 & 2,52 &, 561 & 1,33 & 4,00 & \\
& Gastronomi & 46 & 2,81 &, 569 & 1,33 & 4,00 &, $017^{*}$ \\
\hline YKK & Tí/ Tío & 50 & 3,33 &, 649 & 2,00 & 5,00 & \\
& Tur. Reh. & 45 & 2,78 &, 704 & 1,33 & 4,67 & \\
& Gastronomi & 46 & 3,22 &, 740 & 2,00 & 4,67 &, $000^{*}$ \\
\hline
\end{tabular}

Tablo 3: Bölüm değişkenine bağlı istatistikler

Tablo 3 incelendiğinde bölüm değişkeninin “dil dersine yönelik ilgi” ve "yabancılarla konuşma kaygısı” boyutlarında anlamlı farklılıklara rastlandığı belirlenmiştir. Hangi bölümler arası anlamlı farklılıkların bulunduğu yapılan Post-Hoc Tukey testleri ile hesaplanmıştır. "Dil dersine yönelik ilgi" boyutunda Turizm İşletmeciliği/ Turizm İşletmeciliği ve Otelcilik bölümü ile Gastronomi bölümü arasında $(p=, 031<, 05)$ ve Turizm Rehberliği bölümü ile Gastronomi bölümü arasında $(p=, 041<, 05)$ anlamlı farklılıklar gözlenmiştir. Yapılan hesaplamalara göre Gastronomi bölümü öğrencilerinin yabancı dil dersine yönelik ilgilerinin $(X=2,81)$ TÍ/ TİO bölümü öğrencilerine $(X=2,52)$ ve Turizm Rehberliği bölümü öğrencilerine $(X=2,52)$ göre daha yüksek olduğu söylenebilir. "Yabancılarla konuşma kaygısı" boyutu incelendiğinde ise Tİ/ TİO bölümü ile Turizm Rehberliği bölümü arasında $(p=, 001<, 05)$ ve Gastronomi bölümü ile Turizm Rehberliği bölümü arasında $(\mathrm{p}=, 009<, 05)$ anlamlı farklılıklar tespit edilmiştir. Yapılan hesaplamalara göre Tİ/ TİO bölümü öğrencilerinin yabancılarla konuşma kaygılarının $(X=3,33)$ Turizm Rehberliği öğrencilerine $(X=2,78)$ göre; Gastronomi bölümü öğrencilerinin yabancılarla konuşma kaygılarının $(X=3,22)$ ise Turizm Rehberliği öğrencilerine $(X=2,78)$ göre daha yüksek olduğu söylenebilir. "Dil dersinde konuşma kaygısı" boyutunda ise anlamlı bir farklılık söz konusu değildir.

Katılımcıların yabancı dil dersi kaygılarının sınıf düzeylerine göre anlamlı bir şekilde farklılaşıp farklılaşmadığı tek yönlü varyans analizi (AVONA) testlerinden Post-Hoc Tukey testi kullanılarak hesaplanmıştır. Post-Hoc Tukey testlerine ilişkin istatistiki sonuçlar Tablo 4’te verilmiştir. 


\begin{tabular}{llcccccc}
\hline Boyut & Sinıf & N & X & SD & Min. & Max. & p \\
\hline DDKK & & & & & & & \\
& 2. Sinıf & 44 & 2,81 &, 740 & 1,63 & 4,26 & \\
& 3. Sinıf & 42 & 3,01 &, 702 & 1,63 & 4,05 & \\
& 4. Sinıf & 55 & 3,01 &, 619 & 1,74 & 4,21 &, 271 \\
\hline DDYİ & & & & & & & \\
& 2. Sinıf & 44 & 2,51 &, 716 & 1,33 & 4,00 & \\
& 3. Sinıf & 42 & 2,54 &, 540 & 1,67 & 3,67 & \\
& 4. Sinıf & 55 & 2,75 &, 469 & 1,67 & 3,67 &, 076 \\
\hline YKK & & & & & & & \\
& 2. Sinıf & 44 & 3,25 &, 736 & 1,67 & 4,67 & \\
& 3. Sinıf & 42 & 3,14 &, 776 & 1,33 & 5,00 & \\
& 4. Sinıf & 55 & 3,00 &, 684 & 2,00 & 4,33 &, 216 \\
\hline
\end{tabular}

Tablo 4: Sınıf düzeyi değişkenine bağlı istatistikler

Tablo 4 incelendiğinde sınıf düzeyine ilişkin boyutlar arasında herhangi anlamlı bir farklılık tespit edilememiştir.

Katılımcıların yabancı dil dersi kaygılarının seçtikleri yabancı dillere göre anlamlı bir şekilde farklılaşıp farklılaşmadığı tek yönlü varyans analizi (AVONA) testlerinden Post-Hoc Tukey testi kullanılarak hesaplanmıştır. Post-Hoc Tukey testlerine ilişkin istatistiki sonuçlar Tablo 5 'te verilmiştir.

\begin{tabular}{llllllll}
\hline Boyut & $\begin{array}{l}\text { Yabancı } \\
\text { Dil }\end{array}$ & $\mathbf{N}$ & $\mathbf{X}$ & SD & Min. & Max. & p \\
\hline DDKK & & & & & & & \\
& Almanca & 45 & 2,95 &, 645 & 1,63 & 4,26 & \\
& Fransizca & 58 & 3,04 &, 638 & 1,74 & 4,21 & \\
& İtalyanca & 38 & 2,82 &, 789 & 1,63 & 3,95 &, 307 \\
\hline DDYI & & & & & & & \\
& Almanca & 45 & 2,68 &, 681 & 1,33 & 4,00 & \\
& Fransizca & 58 & 2,60 &, 522 & 1,33 & 3,67 & \\
& İtalyanca & 38 & 2,56 &, 554 & 1,67 & 4,00 &, 640 \\
\hline YKK & & & & & & & \\
& Almanca & 45 & 3,15 &, 790 & 1,67 & 5,00 & \\
& Fransizca & 58 & 2,95 &, 712 & 1,33 & 4,67 & \\
& İtalyanca & 38 & 3,33 &, 643 & 2,00 & 4,67 &, $046 *$
\end{tabular}

Tablo 5: Seçilen yabancı dil değiş̧kenine bağlı istatistikler 
Tablo 5 incelendiğinde seçilen yabancı dil değişkeninin yalnızca "yabancılarla konuşma kaygısı" boyutunda anlamlı bir şekilde farklılık gösterdiği belirlenmiştir. Hangi diller arası anlamlı farklılıkların bulunduğu yapılan Post-Hoc Tukey testleri ile hesaplanmıştır. "Yabancılarla konuşma kaygısı" boyutunda Fransızcayı seçen öğrenciler ile İtalyancayı seçen öğrenciler arasında anlamlı farklılıklar $(p=, 046<, 05)$ gözlenmiştir. Yapılan hesaplamalara göre seçmeli yabancı dil olarak İtalyanca seçen öğrencilerin yabancılarla konuşma kaygılarının $(X=3,33)$ yabancı dil olarak Fransızca seçen öğrencilere $(X=2,95)$ göre daha yüksek olduğu belirlenmiştir. Yapılan hesaplamalar, diğer boyutlarda anlamlı farklılıkların bulunmadığını ortaya koymaktadır.

Katılımcıların yabancı dil dersi kaygılarının başarı durumlarına göre anlamlı bir şekilde farklılaşıp farklılaşmadığı tek yönlü varyans analizi (AVONA) testlerinden Post-Hoc Tukey testi kullanılarak hesaplanmıştır. Post-Hoc Tukey testlerine ilişkin istatistiki sonuçlar Tablo 6'da verilmiştir.

\begin{tabular}{llcccccc}
\hline Boyut & $\begin{array}{l}\text { Başarı } \\
\text { Durumu }\end{array}$ & $\mathbf{N}$ & $\mathbf{X}$ & SD & Min. & Max. & p \\
\hline DDKK & & & & & & & \\
& $1,00-2,00$ & 3 & 3,49 &, 151 & 3,32 & 3,58 & \\
& $2,01-2,50$ & 21 & 2,90 &, 623 & 1,84 & 3,84 & \\
& $2,51-3,00$ & 51 & 2,91 &, 629 & 1,63 & 4,11 & \\
& $3,01-4,00$ & 66 & 2,96 &, 755 & 1,63 & 4,26 &, 556 \\
\hline DDYI & & & & & & & \\
& $1,00-2,00$ & 3 & 2,44 &, 384 & 2,00 & 2,67 & \\
& $2,01-2,50$ & 21 & 2,85 &, 671 & 1,33 & 4,00 & \\
& $2,51-3,00$ & 51 & 2,66 &, 621 & 1,33 & 4,00 & \\
& $3,01-4,00$ & 66 & 2,51 &, 510 & 1,33 & 3,67 &, 101 \\
\hline YKK & $1,00-2,00$ & 3 & 3,44 &, 192 & 3,33 & 3,67 & \\
& $2,01-2,50$ & 21 & 3,22 &, 811 & 1,33 & 4,67 & \\
& $2,51-3,00$ & 51 & 3,07 &, 770 & 1,67 & 4,67 & \\
& $3,01-4,00$ & 66 & 3,11 &, 695 & 2,00 & 5,00 &, 764 \\
\hline
\end{tabular}

Tablo 6: Başarı durumu değişkenine bağlı istatistikler

Tablo 6 incelendiğinde başarı durumuna ilişkin boyutlar arasında herhangi anlamlı bir farklılık tespit edilememiştir.

Katılımcıların yabancı dil dersi kaygılarının mezun olduklarında turizm alanında çalışıp çalışmak istemediklerine göre anlamlı bir şekilde farklılaşıp farklılaşmadığı tek yönlü varyans analizi (AVONA) testlerinden Post-Hoc Tukey testi kullanılarak 
hesaplanmıştır. Post-Hoc Tukey testlerine ilişkin istatistiki sonuçlar Tablo 6'da verilmiştir.

\begin{tabular}{lllllllc}
\hline Boyut & $\begin{array}{l}\text { Meslek } \\
\text { Olarak } \\
\text { Turizm }\end{array}$ & $\mathbf{N}$ & $\mathbf{X}$ & SD & Min. & Max. & p \\
\hline DDKK & Evet & 59 & 3,14 &, 589 & 1,63 & 4,11 & \\
& Hayır & 26 & 2,63 &, 686 & 1,63 & 4,21 & \\
& Kararsizım & 56 & 2,90 &, 726 & 1,63 & 4,26 &, $005^{*}$ \\
\hline DDYİ & & & & & & & \\
& Evet & 59 & 2,59 &, 474 & 1,33 & 3,67 & \\
& Hayır & 26 & 2,46 &, 639 & 1,67 & 4,00 & \\
& Kararsizım & 56 & 2,71 &, 649 & 1,33 & 3,67 &, 178 \\
\hline YKK & & & & & & & \\
& Evet & 59 & 3,00 &, 679 & 1,67 & 4,67 & \\
& Hayır & 26 & 3,11 &, 821 & 1,33 & 4,67 & \\
& Kararsizım & 56 & 3,25 &, 733 & 2,00 & 5,00 &, 202 \\
\hline
\end{tabular}

Tablo 7: Turizm alanında çalmayı isteyip istememe değişkenine bağlı istatistikler

Tablo 7 incelendiğinde öğrencilerin mezun olduklarında turizm alnında çalışmayı isteyip istemedikleri değişkeninin yalnızca "dil dersinde konuşma kaygısı" boyutunda anlamlı bir şekilde farklılık gösterdiği belirlenmiştir. Hangi değişkenler arası anlamlı farklılıkların bulunduğu yapılan Post-Hoc Tukey testleri ile hesaplanmıştır. "Dil dersinde konuşma kaygısı" boyutunda mezun olduğunda turizm alanında çalışmak istediğini söyleyen öğrenciler ile mezun olduğunda turizm alanında çalışmak istemediğini söyleyen öğrenciler arasında anlamlı farklılıklar $(p=, 005<, 05)$ gözlenmiştir. Yapılan hesaplamalara göre mezun olduklarında turizm alanında çalışmak isteyen öğrencilerin dil dersinde konuşma kaygılarının $(X=3,14)$ mezun olduklarında turizm alanında çalışmak istemeyen öğrencilere $(X=2,63)$ göre daha yüksek olduğu belirlenmiştir. Yapılan hesaplamalar, diğer boyutlarda anlamlı farklılıkların bulunmadığını ortaya koymaktadır.

Sonuç olarak yapılan incelemelerde katılımcıların yabancı dil derslerine yönelik kaygılarında yalnızca sınıf düzeylerine ve başarı durumlarına göre anlamlı farklılıklar bulunamadığ 


\section{Sonuç ve Tartışma}

$\mathrm{Bu}$ çalışmada, Turizm Fakültesi öğrencilerinin seçmeli yabancı dil derslerine yönelik kaygılarının cinsiyet, bölüm, sınıf düzeyi, seçilen yabancı dil, başarı durumu ve turizm alanında çalışmak istenip istenmediği gibi farklı değişkenler açısından incelenmesi amaçlanmıştır. Çalışma, nicel araştırma yöntemlerinden tarama modelinde tasarlanmış olup 141 katılımcı ile gerçekleştirilmiştir. Katılımcıların \%46,1'i kadın, \%53,9'u ise erkektir.

Çalışmada, katılımcıların seçmeli yabancı dil derslerine yönelik kaygılarının cinsiyet değişkenine bağlı olarak yalnızca "dil dersinde konuşma kaygısı" boyutunda anlamlı bir farklılık ( $\mathrm{p}=, 000<, 05)$ gösterdiği; "dil dersinde konuşma kaygısı" boyutunda erkek öğrencilerin $(X=3,18)$ kadın öğrencilere $(X=2,68)$ göre daha kaygılı oldukları belirlenmiştir. Literatür incelendiğinde çalışmada elde edilen sonuçlara benzer sonuçlara (Tuncer/ Temur 2017; Tuncer/ Doğan 2015) ulaşıldığ1 gibi çalışmada elde edilen sonuçlarla uyuşmayan çalışmalarla karşılaşılmıştır. Bazı araştırmacılar (Boylu/ Cangal 2015; Genç 2009; Gedik 2015; Özkan/ Kınay 2015) öğrencilerin yabancı dil derslerine yönelik kaygılarının cinsiyet değişkenine göre değişmediğini ifade ederken bazı araştırmacılar ise (Aşık/ Gökçe 2019) kadın öğrencilerin yabancı dil derslerindeki kaygılarının erkek öğrencilere göre daha yüksek olduğu belirtilmektedir.

Katılımcıların yabancı dil derslerine yönelik kaygılarının eğitim alınan bölüm değişkenine bağlı olarak "dil dersine yönelik ilgi” ve "yabancılarla konuşma kaygısı" boyutlarında anlamlı bir şekilde farklılaştığ $(p=, 017<, 05$ ve $p=, 000<, 05)$ tespit edilmiştir. "Dil derslerine yönelik ilgi" boyutunda Gastronomi bölümü öğrencilerinin $(X=2,81)$ yabancı dil dersine yönelik ilgilerinin Tİ/ TİO bölümü öğrencilerine $(X=2,52)$ ve Turizm Rehberliği bölümü öğrencilerine $(X=2,52)$ göre daha yüksek olduğu belirlenmiştir. "Yabancılarla konuşma kaygısı" boyutunda Tİ/ TİO bölümü öğrencilerinin $(\mathrm{X}=3,33)$ yabancılarla konuşma kaygılarının Turizm Rehberliği öğrencilerine $(X=2,78)$ göre; Gastronomi bölümü öğrencilerinin $(X=3,22)$ yabancılarla konuşma kaygılarının ise Turizm Rehberliği öğrencilerine $(X=2,78)$ göre daha yüksek olduğu gözlenmiştir. Konu ile ilgili alanyazın tarandığında yapılmış çalışmalarda (Tuncer/ Doğan 2015; Koç Akran/ Özdemir 2018; Sevim 2014; Okul, Hafçi/ Öncüer Çivici 2017) öğrencilerin konuşma kaygılarının eğitim aldıkları bölümlere göre anlamlı bir şekilde farklılaşmadığı tespit edilmiştir.

Çalışmada yer alan katılımcıların yabancı dil derslerine yönelik kaygıları eğitim aldıkları sınıf düzeyi değişkenine göre incelendiğinde anlamlı herhangi bir farklılığın saptanmadığı belirlenmiştir. İncelenen çalışmalarda benzer sonuçlarla karşılaşıldığı gibi farklı sonuçlarla da karşılaşılmıştır. Gedik (2015) ve Kozikoğlu ve Kanat (2018) konuşma kaygısının sınıf düzeyine göre anlamlı bir şekilde farklılaşmadığını savunurken Özkan ve Kınay (2015) ve Şener (2018) ise öğrencilerin konuşma kaygılarının son sınıfa doğru gidildikçe düştüğünü tespit etmiştir.

Katılımcıların yabancı dil derslerine yönelik kaygılarının seçtikleri yabancı dil değişkenine bağlı olarak yalnızca "yabancılarla konuşma kaygısı" boyutunda anlamlı bir şekilde $(p=, 046<, 05)$ farklılaştı̆̆ 1 saptanmıştır. "Yabancılarla konuşma kaygısı" 
boyutunda yabancı dil olarak İtalyanca seçen öğrencilerin $(X=3,33)$ yabancılarla konuşma kaygılarının yabancı dil olarak Fransızca seçen öğrencilere $(X=2,95)$ göre daha yüksek olduğu tespit edilmiştir.

Çalışmada, katılımcıların yabancı dil derslerine yönelik kaygıları başarı durumu değişkenine bağlı olarak incelendiğinde anlamlı herhangi bir farklılığa rastlanmadığ belirlenmiştir. Taranan alanyazında Batumlu ve Erden (2007) tarafindan yapılmış araştırmada farklı bir sonuca ulaşılmış, başarı durumu düşük öğrencilerin yabancı dil kaygılarının başarı durumu yüksek öğrencilere göre daha yüksek olduğu ortaya konmuştur.

Çalışmada elde edilen bulgular 1şığında, katılımcıların yabancı dil derslerine yönelik kaygıları mezun olduklarında turizm alanında çalışmak isteyip istememeleri değişkenine bağlı olarak yalnızca "dil derslerinde konuşma kaygısı" boyutunda anlamlı bir şekilde $(p=, 005<, 05)$ farkl1lık göstermiştir. "Dil dersinde konuşma kaygısı" boyutunda, mezun olduklarında turizm alanında çalışmak isteyen öğrencilerin $(X=3,14)$ dil dersinde konuşma kaygılarının, mezun olduklarında turizm alanında çalışmak istemeyen öğrencilere $(X=2,63)$ göre daha yüksek olduğu gözlenmiştir.

Turizm Fakültelerinde eğitim alan öğrencilerin yabancı dil derslerine yönelik kaygılarının azaltılması amacıyla yabancı dilin önemine ve düşünüldüğü kadar zor olmadığına yönelik bilgilendirme seminerlerinin verilmesinin; yabancı dil ders saatlerinin artırılarak öğrencilerin yabancı dile daha çok maruz bırakılmasının ve gelecekte bu çalışmanın daha yüksek bir katılımcı sayısı ile ve daha geniş bir örneklemde yapılmasının yerinde olacağı düşünülmektedir.

\section{Kaynakça}

Akgöz, Erkan/ Gürsoy, Yüksel (2014): Turizm eğitimde yabancı dil öğrenme istek ve kararlılıkları: Selçuk Üniversitesi Beyşehir örneği. Journal of Tourism and Gastrnomy Studies, 2(1), 21-29.

Akoğlan Kozak, Meryem (2009): Akademik turizm eğitimi üzerine bir durum analizi. Muğla Üniversitesi Sosyal Bilimler Enstitüsü Dergisi (ILLKE), 22, 1-20.

Akşit Aşık, Nuran/ Gökçe, Faruk (2019): Yabancı dil konuşma kaygısını etkileyen faktörler: Turizm Lisans öğrencileri üzerinde bir araştırma. Güncel Turizm Araştırmaları Dergisi, 3(2), 202-219.

Altürk, Abdulvahap/ Yel, Gökhan/ Arık Yüksel, Tuğba/ Balcı, Umut (2016): Turizm Fakülte ve Yüksekokullarında yabancı dil eğitimi. Turkish Studies, 11(3), 139-150.

Aydın, Selami/ Zengin, Buğra (2008): Yabancı dil öğreniminde kaygı. Dil ve Dil Bilimi Çalışmaları Dergisi, 4(1), 1-94.

Baş, Gökhan (2014): Lise öğrencilerinde yabancı dil öğrenme kaygısı: Nitel bir araştırma. Pamukkale Üniversitesi Ĕ̈itim Fakültesi Dergisi, 36(2), 101-119.

Batumlu, Didar Zeynep/ Erden, Münire (2007): Yıldız Teknik Üniversitesi Yabancı Diller Yüksekokulu hazırlık öğrencilerinin yabancı dil kaygıları ile İngilizce başarıları arasındaki ilişki. Ĕ̈itimde Kuram ve Uygulama, 3(1), 24-38. 
Boylu, Emrah/ Çangal, Önder (2015): Yabancı dil olarak Türkçe öğrenen Bosna-Hersekli öğrencilerin konuşma kaygılarının çeşitli değişkenler açısından incelenmesi. Uluslararası Türkçe Edebiyat Kültür Ĕ̆itim Dergisi, 4(1), 349-368.

Büyükkalay, Nurgül (2016): Avrupa dilleri ögretimi ortak çerçeve programı temelli özel amaçl Ingilizce konuşma ve dinleme becerileri etkinliklerinin Turizm Fakültesi öğrencilerinin başarısı üzerindeki etkileri. Yayımlanmamış Yüksek Lisans Tezi. Antalya: Akdeniz Üniversitesi Eğitim Bilimleri Enstitüsü.

Çelebi, Mustafa Durmuş (2006): Türkiye'de anadili eğitimi ve yabancı dil öğretimi. Erciyes Üniversitesi Sosyal Bilimler Enstitüsü Dergisi, 21, 285-307.

Davras, Gonca Manap/ Bulgan, Gülay (2012): Meslek Yüksekokulu (MYO) öğrencilerinin İngilizce hazırlık eğitimine yönelik tutumları: Isparta MYO Turizm ve Otel İşletmeciliği örneği. Doğuş Üniversitesi Dergisi, 13(2), 227-238.

Doğan, Türkan/ Çoban, Aysel Esen (2009): Eğitim Fakültesi öğrencilerinin öğretmenlik mesleğine yönelik tutumları ile kaygı düzeyleri arasındaki ilişkinin incelenmesi. Eğitim ve Bilim, 34(153), 157-168.

Duman, Bilal/ Göral, Güldehan Neşe/ Bilgin, Hilal (2017): Üniversite öğrencilerinin sınıf ortamında yabancı dil konuşma kaygısı üzerine nitel bir çalışma. Adnan Menderes Üniversitesi Ĕgitim fakültesi Ĕgitim Bilimleri Dergisi, 8(2), 13-27.

Gedik, Mehmet (2015): Siirt örnekleminde ortaöğretim öğrencilerinin konuşma kaygılarının incelenmesi. ODÜ Sosyal Bilimler Araştırmaları Dergisi, 5(13), 77-93.

Genç, Gülten (2009): İnönü Üniversitesi Yabancı Diller Yüksekokulu öğrencilerinin yabancı dil kayg1lar1. Education Sciences, 4(3), 1080-1088.

Gürsu, Fatma (2011): The Turkish equivalence, validity and reliability study of the foreign language classroom anxiety scale. Yayımlanmamış Yüksek Lisans Tezi. İstanbul: Yeditepe Üniversitesi Sosyal Bilimler Enstitüsü.

Işık, Ali (2008): Yabancı dil eğitimimizdeki yanlışlar nereden kaynaklanıyor? Journal of Language and Linguistic Studies, 4(2), 15-26.

İşigüzel, Bahar (2013): Turizm İşletmeciliği ve Otelcilik programlarındaki mesleki Almanca dersleri üzerine bir araştırma. Humanities Sciences, 8(4), 363-371.

Koç Akran, Sevda/ Özdemir, Elham (2018): Yaşam boyu öğrenme sürecinde öğretmen adaylarının konuşma kaygılarına ilişkin görüşleri. The Journal of International Lingual, Social and Educational Sciences, 4(1), 38-49.

Koçak, Muhammet/ Çobanoğulları, Ferdiye (2017): Dünyada ikinci yabancı dil olarak Almanca öğretiminde Danimarka örneği. Uluslararası Ĕ̆itim Bilimleri Dergisi, 1(1), 1-12.

Kozikoğlu, İshak/ Kanat, Fırat (2018): Lise öğrencilerinin İngilizce dersine katılım durumlarının İngilizce dersine yönelik tutum ve İngilizce konuşma kaygısına göre yordanması. Kastamonu Eğitim Dergisi, 26(5), 1643-1652.

Oktar, Derya (2004): Yabancı dil öğrenimi sürecinde kayg1. Hacettepe Üniversitesi Eğitim Fakültesi Dergisi, 26, 48-53.

Oral, Behçet/ Çoban, Ahmet (2020): Kuramdan Uygulamaya Eğitimde Bilimsel Araştırma Yöntemleri. Ankara: Pegem Akademi.

Özkan, Erdost/ Kınay, İsmail (2015): Öğretmen adaylarının konuşma kaygılarının incelenmesi (Ziya Gökalp Eğitim Fakültesi Örneği). Uluslararası Türkçe, Edebiyat Kültür Eğitim Dergisi, 4(3), 1290-1301. 
Sevim, Oğuzhan (2014): Yabancı uyruklu öğrencilerin Türkçe konuşma kaygılarının bazı değişkenler açısından incelenmesi. EKEV Akademi Dergisi, 18(60), 389-402.

Şen, Ülker (2011): Belçika'da yaşayan Türk çocuklarının Türkçeye yönelik tutumları ve yazma becerileri. Yayımlanmamış Doktora Tezi. Ankara: Gazi Üniversitesi Eğitim Bilimleri Enstitüsü.

Şener, Sabriye (2018): Öğretmen adaylarının yabancı dil derslerinde İngilizce konuşma kaygıları ile ilgili algıları. Trakya Üniversitesi Ë̆itim Fakültesi Dergisi, 8(2), 178-194.

Tuncer Murat/ Akmençe, Ahmet Egemen (2019): Yabancı dile yönelik kaygı, özyeterlik ve tutum arasındaki ilişkiler. Turkish Journal of Educational Studies, 6(3), 1-13.

Tuncer, Murat/ Doğan, Yunus (2015): Hazırlık sınıfı öğrencilerinin yabancı dil ders kaygıları ve akademik özyeterlikleri arasındaki ilişki. Dil ve Edebiyat Eğitimi Dergisi, 14, 153-167.

Tuncer, Murat/ Temur, Mehmet (2017): Yabancı dil hazırlık eğitimi alan öğrencilerin yabanc1 dile yönelik kaygı ve başarıları arasındaki ilişkiler. Dicle Üniversitesi Ziya Gökalp Eğitim Fakültesi Dergisi, (32), 905-912.

Uysal, Davut (2019): Turizm Fakültesi öğrencilerinin İngilizce iletişim becerilerinin geliştirilmesine yönelik gereksinim çözümlemesine dayalı bir program önerisi. Yayımlanmamış Doktora Tezi. Eskişehir: Eskişehir Osmangazi Üniversitesi Sosyal Bilimler Enstitüsü.

Üstün, Bilal (2015): Turizm Fakültelerinde öğretilen Almancanın öğrenciler, sektör temsilcileri ve Alman turistler tarafindan değerlendirilmesi. Yayımlanmamış Yüksek Lisans Tezi. Elâzı̆̆g: Fırat Üniversitesi Sosyal Bilimler Enstitüsü.

Yavuz, Soner/ Akdeniz, Aydın (2019): Fen Bilgisi öğretmen adaylarının tükenmişlik ve KPSS kayg1 düzeylerinin çeşitli değişkenler açısından incelenmesi. Karaelmas Journal of Educational Sciences, 7, 212-227.

Yılmaz Güngör, Zühre (2016): Fransızca yabancı dil öğreniminde kaygı: Nedenleri ve cinsiyet faktörü. The Journal of Academic Social Science Studies, 46, 291-302.

Yılmaz, Didem/ Sakarya Maden, Sevinç (2016): Dil öğrenim sürecinde Almanca öğretmen adaylarının kayg1 tutumlarına ilişkin bir araştırma. Trakya Üniversitesi Eğitim Fakültesi Dergisi, 6(2), 201211. 